\title{
Sinasos (Mustafapaşa) Duvar Resimlerinde Tarihi Bir Konu: Otsu Vakası
}

\author{
A Historic Subject in the Wall Paintings of Sinasos (Mustafapaşa): \\ The Case of Otsu
}

\section{Yıldıray ÖZBEK *}

$\ddot{O}_{z}:$ Bir Kapadokya kasabası olan Sinasos (Mustafapaşa), sıra dışı konuların işlendiği duvar resimlerinin bulunduğu konutlarla dikkati çeken bir yerleşimdir. 19. yüzyılda inşa edildikleri bilinen konutlarda yer alan duvar resimlerinin büyük bölümünde sanatçı imzasına rastlanır. Bu makalede, kasabadaki duvar resimlerinin bir bölümünün ressamı olduğunu bildiğimiz Kostis Meletiadis'in, kasabalı havyar tüccarlarından Haralambos Sultanidis'in evine yaptığı ve yakın tarihten bir konuyu ele alan duvar resmi incelenecektir. Resim, 1891 yılı Mayıs ayında Rus prensi Nikola'nın (1894-1917 arası Rus Çarı) kuzeni Yunan prensi Georgios ile birlikte Japonya'yı ziyaretleri sırasında Otsu'da uğradıkları saldırıyı konu alır. Bildiride Kostis Meletiadis tarafindan olaydan iki yıl sonra (1893) yapılan bu resmin kaynağı ile neden konu olarak seçildiği tartışılacaktır.

Anahtar sözcükler: Duvar resmi, Kapadokya, Mustafapaşa (Sinasos), Otsu

\begin{abstract}
Sinasos, a Cappadocian town, attracts attention with its houses which have some wall paintings that have extraordinary subjects. The signature of the artist is often found on many of the wall paintings in the houses known to have been constructed in 19th century. The subject of this paper is a wall painting of a historical subject painted by Kostis Meletiadis, a painter of some of the wall paintings in the town, in the house of the caviar merchant Haralambos Sultanidis. The subject of this painting is the failed assassination attempt in Otsu in May 1891 on the Russian Prince Nikola (Czar between 1894 and 1917) and his cousin Georgios, the Greek prince, during their common visit to Japan. The paper also focuses on the resources employed for this painting by Kostis Meletiadis in 1893, only two years after this event, and questions why such an event was chosen for the subject of this wall painting in this house in Sianasos.
\end{abstract}

Keywords: Wall Painting, Cappadocia, Mustafapaşa (Sinasos), Otsu

\section{Giriş}

Sinasos (Mustafapaşa) 19. yüzyılın ikinci yarısında nüfusunun dörtte üçü Rumlardan oluşan bir Kapadokya kasabasıdır (Dawkins 1910, 117). Kapadokya bölgesindeki pek çok yerleşimde Rumlar, Türkçe konuşmakta, yapı kitabelerini veya kitaplarını Hellen harfleriyle Türkçe olarak yazmaktayken, Sinasos (Mustafapaşa) kasabasının Rum sakinleri Rumca konuşup yazmaktayd1lar. Kasabanın hem Türk, hem de Rum ahalisinin 19. yüzyılın ikinci yarısından itibaren Kayseri, Adana, Niğde gibi çevre vilayetlere ve özellikle de İstanbul'a çalışmaya gittikleri bilinmektedir. İstanbul'a giden Türklerin genellikle sarayda çeşitli hizmet alanlarında istihdam edildiği, Rumların ise Galata civarında, diğer Rum cemaatleriyle fazla ilişkiye girmeden havyar ve boya

\footnotetext{
* Prof. Dr., Akdeniz Üniversitesi, Edebiyat Fakültesi, Sanat Tarihi Bölümü, Antalya. yozbek@akdeniz.edu.tr
} 
ticaretiyle uğraştıkları çeşitli kaynaklardan öğrenilmektedir. Kaynaklarda zikredilen bilgilerden Sinasoslu Rumların havyarcılar loncasında çok sayıda üyelerinin bulunduğu anlaşılmaktadır (Balta 2007, 62; Çokana 2016, 359). Rumların İstanbul'da ticaretten kazandıkları servet, memleketlerine kesme taş malzemeli, bezemeli balkonlara sahip, bazısı avlulu ve çoğunda iç mekanları duvar resimli konaklar olarak yansımıştır (Özbay 2004, 70; Saner-Yıldırım 2006, 165-179). Kasabanın Rum ahalisinin tamamı 1924 Mübadele Anlaşmasıyla Yunanistan'a gönderilmiştir.

Duvar resmi, Osmanlı sanatında 18. yüzyılın ikinci yarısından sonra görülmeye başlanan bir iç mekan bezeme tarzıdır (Arık 1999, 423; Renda 2002, 268). Sarayla eş zamanlı olarak özel konaklarda da görülen bu tarzda, daha çok insana huzur veren deniz veya göl manzaralı hayali tasvirlerin yanı sıra İstanbul'un Haliç veya Boğaziçi kıyılarıyla, Galata'dan bakılarak betimlenmiş tarihi yarımada tasvirleri de görülür. Genel olarak figüratif anlatımlardan kaçınılan bu tür resimlerin büyük çoğunluğunda özellikle de taşradaki örneklerde sanatçı ismiyle karşılaşılmaz. Sıva üstüne çekilen alçı veya "üstübeç" üzerine suyla karıştırılmış boyalarla yapılan resimlerin 19. yüzyılda ahşap tavanlar veya duvar kaplama tahtasına gerilen deri ya da keten üzerine yapılmış örnekleriyle de karşılaşılmaktadır (Tekinalp 2002, 444).

Sinasos'ta 1870-1910 tarih aralığına yerleştirilen duvar resimleri pek çok açıdan yukarıda bahsedilen genellemelerin dışında özellikler sunar. Hayali veya gerçek kent tasvirlerinin yanı sıra, belirli bir konuyu ele alan figüratif kompozisyonların çoğunda tarih ve sanatçı imzasını görmek mümkündür. Georgios Iordanidis ve Kostis Meletiades imzalarına en sik rastlanan sanatçılardır. Çevredeki 19. yüzyıl kiliselerinde de çalışmaları olduğunu bildiğimiz Georgios Iordanidis'in Canseverler Konağı, Temel Öztürk Evi ve Mustafa Savaş Evi'ne yaptığı resimler, Osmanlı duvar resimleri içinde sıra dışı konularıyla özel bir yer tutmakla birlikte, kasabanın 19. yüzyılda yaşadığı kültürel ilişkileri de ortaya koyar. Sözgelimi Canseverler Konağı'nda bulunan ve Hellenistik dönemden bir olay olan "Apelles'e Iftira Atılması" konulu resim (Özbek 2016, 381-398) dönem örnekleri içinde benzeri olmayan ünik bir anlatımdır.

$\mathrm{Bu}$ bildiriye konu olan resim de içeriği bakımından benzeri olmayan bir tasvir olup, 19. yüzyılın sonlarında yaşanmış bir olayı anlatmaktadır. Resim Mübadele öncesi kasaba sakinlerinden Haralambos Sultanidis'in 1892 y1linda inşa edilmiş gösterişli konağında bulunmaktadır. Ev sahibi Sultanidis'in bir armatör olduğunu ileri sürenler vardır (Korat 2005, 263).

Resim konağın dört sütuna atılan kemerlerin taşıdığ ahşap tavanlı geniş salonunun güney cephesinde, giriş kapısının üzerinde, kapı penceresi ile tavan arasındaki yüzeye işlenmiştir (Fig. 1). Kahverengi bir bordürle çerçevelenen resmin merkezinde üç figür bulunmaktadır. Figürlerden izleyiciye göre sağda yer alanı sandaletleri ve dizleri üzerinde biten kısa etekli giysisi ile diğer iki figürden ayrılmış; adeta bir Romalı asker gibi betimlenmiştir. Sağ elindeki kılıciyla en soldaki figüre hamle yapmış pozisyondadır. Ceket, pantolon ve kravatıyla diğer iki figür dönem modasına uygun bir giyim kuşamla ve miğferi andıran birer başlıkla resmedilmişlerdir. Soldaki figürün aldığ darbeyle başlı̆g 1 düşmüştür ve sol eliyle yaralanan başını tutmaktadır. Ortadaki figür bu kavgayı

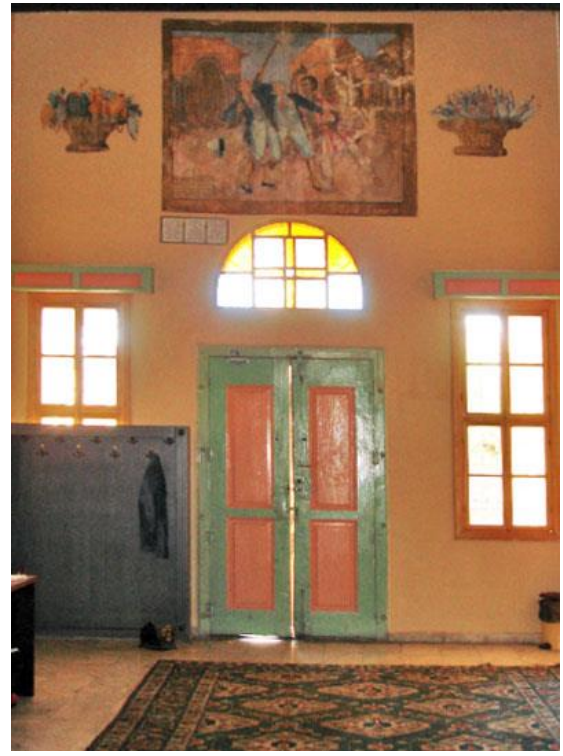

Fig. 1. Mustafapaşa (Sinasos), Haralambos Sultanidis Evi. Rus Prensine Suikast konulu duvar resmi genel görünüş 
ayırmak istercesine sağ elinde tuttuğu sopayla solundaki figüre hamle yapar pozisyondadır. Arka fonda üçlü sütun demetine atılmış yuvarlak kemerli revağı ve kırma çatısıyla Uzakdoğu tapınaklarını hatırlatan üç yapı yer almaktadır. Ayrıca oldukça zor seçilen kalabalıklarda gösterilmeye çalışılmıştır. İzleyiciye göre resmin sol alt köşesinde, dikdörtgen bir çerçeve içine bazı harf yanlışlıklarıyla yazılmış Rumca bir kitabe ile resmin sanatçısı olarak K. Meletiades ismi ve 1893 tarihi görülmektedir (Fig. 2). Beş satır halinde Rum harfleriyle yazılan kitabede:

H EN OTऽOY АПОПЕIPA $\triangle \mathrm{O} \Lambda \mathrm{O}-$ ФONIKH ПАРА ТOY IAП $\Omega N O \Sigma . .$.

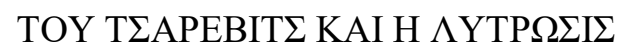
AYTOY ПAPA TOY ГENNAIAN

\section{E $\Lambda$ HNO $\Sigma$ BA II IAN ГЕ $\Omega$ PГIOY}

“'Otsu'da Japon ... tarafindan Çar'ın oğluna karşı düzenlenen cinayet teşebbüsü ve Yunan kralının oğlu George tarafindan kurtarllışı" anlamında ibareler yer alır.

Resim, yakın tarihten bir olay1; 1891 yılı Mayı'ında Japonya'da, 1894-1917 y1lları arasında II. Nikola adıyla çar olacak olan Rus prensi Nikola'ya, Japon polis

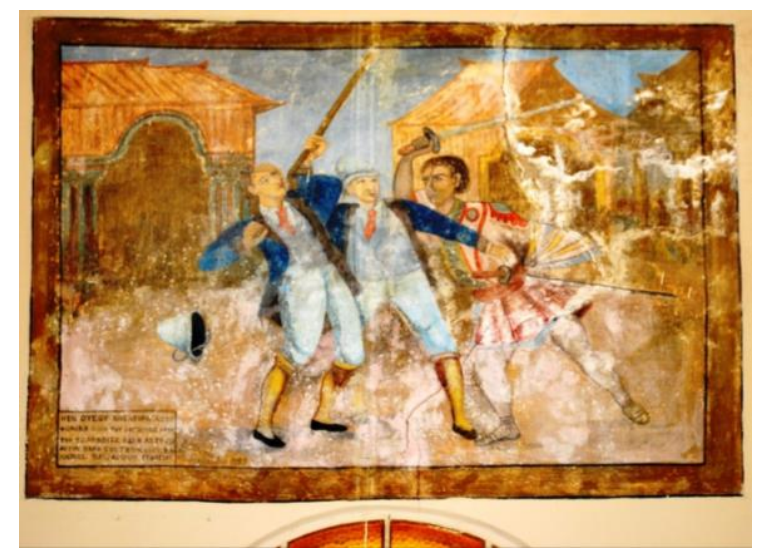

Fig. 2. Mustafapaşa (Sinasos), Haralambos Sultanidis Evi. Rus Prensine Suikast konulu duvar resmi detay1 teşkilatında görevli Tsuda Sanzo tarafından gerçekleştirilen ve yaralanmayla sonuçlanan suikast girişimini anlatmaktadır.

Prens Nikola 1890 yılı Kasım ayı başlarında, ağırlıklı olarak Çin, Hindistan ve Japonya'yı kapsayacak olan ve inşası düşünülen Trans-Sibirya demiryolu projesiyle ilgili görüşmeler yapmak üzere yaklaşı 9,5 ay sürecek olan bir geziye çıkmıştır. St. Petersburg'tan yola çıkan ve Trieste'ye ulaşan ekipte donanma doktoru von Rambach, resmi tarihçi Ukhtomsky ve ressam Gritsenko ile birlikte toplam sekiz kişi bulunmaktadır. Ekibe Atina'da Yunan kralının oğlu ve Nikola'nın kuzeni olan prens George'de katılır (Sin 1989, 142). Yola çıkıştan altı ay sonra nihayet 27 Nisan 1891'de Japonya'ya ulaşan heyet Nagasaki, Kagoshima, Kobe gibi kentleri gezip 9 Mayıs 1891'de trenle Kobe'den Kyoto'ya geçer (Sin 1989, 142). 11 Mayıs'ta Nikola ve ekip Kyoto'nun 5 mil doğusunda Biwa Gölü kenarındaki Otsu şehrini gezmeye giderler. Nikola, Otsu'da Japon Budist tapınaklarının en eskilerinden biri olan Mitsuidera'yı ziyaret eder. Tapınağın arkasında onunla aynı avlu içerisinde bulunan Shiragi Zenshindo adında küçük bir yapı daha vardır. $\mathrm{Bu}$ yapıda, göç günlerinden kalma ve Japonların atası olduğuna inanılan bir ahşap heykel bulunmaktadır. Bu heykelin aslında Koreli bir şamanı betimlediği ileri sürülür. Ayrıca tapınakta altın yaldızlı bronzdan bir Buddha heykeli ile Budist bir yazıtta saklanmaktaydı ve Nikola ve ekibi bu hazineleri görememişti (Sin 1989, 61). Nikola'ya suikast girişiminde bulunan Tsuda Sanzo'nun saldırı için tapınakta hazırlandığı belirtilir. Ekip ve Nikola Otsu'dan Kyoto'ya ikamet ettikleri otele dönerken, onları yoldaki kalabalıktan korumakla görevli bir polis olduğu belirtilen ve samuray kültürüyle yetiştiği ileri sürülen Tsuda Sanzo'nun saldırısına uğradı. Birkaç gün Kyoto'da kalan Nikola ve yanındakiler 13 Mayıs'ta Kobe'ye döndüler ve 19 Mayıs'ta da Vladivostok'a gitmek üzere Japonya'dan ayrildılar (Sin 1989, 142-143). Japon imparatoru prensi ziyaret etmiş, Rusya'dan özür dilenmiş, Tsuda Sanzo yakalanıp ölüm cezasına çarptırılmıştır.

Konuyla ilgili olarak 1989 yılında hazırlanmış bir doktora tezinden alıntılayarak anlattığım 
bu tarihi olayın Sinasos'la ilişkisi ve görsel olarak, armatör olduğu ileri sürülen ev sahibi Haralambos Sultanidis'in konağına nasıl ulaştı̆̆ ve yakın tarihli çok özel bir konu olarak neden seçildiği üstünde durulması gereken bir mevzudur.

Otsu Vakasıly ilgili erken tarihli haber ve görsel malzeme Le Petit Journal Supplément Illustré'nin 30 Mayıs 1891 tarihli sayısında yayınlanmıştır. Derginin 8. sayfasında, Rus prensinin Hindistan ziyaretinden sonra detaylı bir gezi için Japonya'ya geçtiği ve orada yerel bir polis memuru tarafından kılıçla başından yaralandığı belirtilerek, prens George'nin araya girerek ikinci bir hamleyi önlediği kaydedilerek olay şöyle haber yapılır:

"Otsu Vakası (Rus Prensine Saldırı)

Birkaç gün önce Daru caddesindeki Rus Kilisesi'nde, bir şükran töreni düzenlendi. Törende yalnizca Rus ve yabancı diplomatlar veya Cumhurbaşkanının resmi temsilcisi olan Lichtensteinl albay yoktu. Rus cemaatinin pek çok üyesi ve çok sayıda Fransız da tören de mevcuttu. Ve papa Tanrı'ya Çar'ın büyük oğlunun hayatını bağışlaması dolayısıyla şükrederken herkes derin bir heyecan içindeydi. Şayet bu denli sevilen ve Avrupa'da bu derece yüksek bir konumda bulunan genç prens bu fanatik Japon'dan aldığ kılıç darbesi ile ölseydi ne olurdu kim bilir. Neyse ki Yunanistan kralının ikinci oğlu ve Rus prensinin kuzeni olan soğukkanlı ve çevik prens George sayesinde olay oldukça hafif atlatıld ve muhtemelen Supplement Illustré de yer aldı̆̆ zaman kurban bu yarayı artık hissetmiyor olacak. Bilindiği üzere prens Hindistan'a yaptı̆̆ bir ziyaretin ardindan daha detayl gezmek üzere Japonya'ya geçmişti. Otsu'da yerel bir polis memuru kendisine saldird ve onu kllıciyla başlndan yaraladl. Prens George bir sopa ile araya girdiğinde alçak adam ikinci darbeye hazırlanıyordu. Şöyle üç parmak kadar kanayan yara neyse ki pek derin değildi ve prens derhal Kyoto'ya götürüldü. Doğal olarak bu olay Japonya'da bir heyecan dalgast yaratt. Japonya imparatoru maiyetinden bir prensi gönderdikten sonra bizzat kendisi yaral prensin ziyaretine gitti ve onu olabilecek en iyi durumda buldu. Bu saldirtya ilişkin olarak çok şey söylendi. Absürt bir şekilde nihilistleri suçladılar. Japonlar da bir Avrupalyy kendilerinden biri olarak görmedikleri için bir nevi suçluydular. Olayın faili bir Japon'du. Acaba bir deli miydi? Hoş karşılamadığı Avrupalı medeni reformlara karşı olan irticacı bir fanatik miydi? Yakın bir gelecekte bu soruların cevabını bulacağız. Her halükarda şöyle veya böyle bir suçlama yapmamak mantıklı ve insanı bir davranış olacaktır".

Haberin altında neredeyse tüm sayfayı kaplayacak şekilde olayın anlatıldığı resim görülür (Fig. 3). Resim, Le Petit Journal Supplément Illustré'nin muhtelif sayılarında seksenden fazla çalışması olduğu bilinen ve ayrıca Jules Verne'in romanlarını yayınc1 Hetzel için resimlemiş olan karikatürist ve illüstratör Henri Meyer (1844-1899) tarafından yapılmıştır (bk. Web Galery; Galerie Drylewicz). Olaydan 19 gün sonra yayınlanan dergideki bu resmin Sinasos (Mustafapaşa) Haralambos Sultanidis konağındaki resme kaynak olduğu tartışmasızdır. Küçük bir Kapadokya kasabası olarak Sinasos'un 19. yüzyılın ikinci yarısıyla birlikte kayda değer bir ekonomik ve kültürel dönüşüm yaşadığ 1 dönem kaynakları ve günümüze ulaşan konut ve anıtlardan anlaşılmaktadır. Tanzimat Fermanının ilanından sonra 1840 yılında kasabalı kimi hayırsever tüccarların desteğiyle erkekler için bir okul inşa edilmiştir. 
Okulda antik Hellence'yle birlikte Kathaverusa diye adlandırılan ve dönem aydınları ile kilisenin kullandığı Hellence öğretilmeye çalışılmıştır. Din dersinde Eski Ahit'ten parçalar okunmakta, kilise tarihiyle birlikte Ksenophon'un "Kyros'un Eğitimi" isimli eseri de okunan yapıtlar arasında görülmektedir (Balta 2007, 101-103). On siniflı bu okulda, ayin ve temsiller için kullanılan büyük bir salonla birlikte 1500 cilt kitaba sahip olduğu belirtilen bir de kütüphane bulunmaktadır. 1900 yılında okuldaki 250 öğrencinin lisan, matematik, din, tarih, güzel yazı, resim ve müzik dersleri ald1klar1 belirtilir (Stamatopoulos 1985, 4446). 1872 y1lında kasabaya kızlar için de bir okul inşa edilmiş, öğretmen olarak Atina Arsekeio Lisesi'nden mezun Eleni Haralambus atanmıştır. Sonraki yıllarda kasaba halkı, kız okulunda öğretmenlik yapabilecek gençlerini Atina'da okutmak üzere burslar sağlamıştır (Balta 2007, 114).

Kasaba ahalisinden pek çok kişi İstanbul'a çalışmaya gidip, havyar ve boya ticaretiyle uğ-

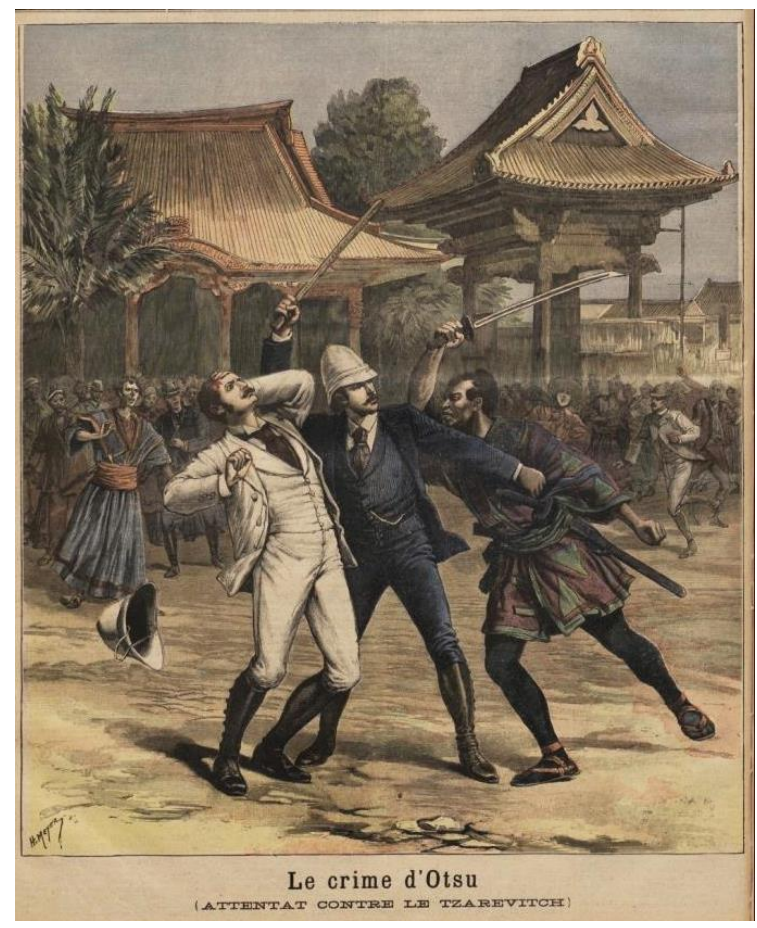

Fig. 3. Rus Prensine Otsu'da (Japonya) Suikast girişimi. Le Petit Journal Supplément Illustré 30 May1s 1891, 8 (gallica.bnf.fr/ark:/12148/bpt6k71 5914p/f8.item 16 Nisan 2017 tarihli erişim) raşıp, kasabalarına konut, okul vb. gibi yapılar inşa ettirmişlerdir. Kasabanın merkezinde Mesohori olarak adlandırılan bölgeye, İstanbul'da havyar ticaretiyle uğraşan Hristo Fergarinas adlı tüccar tarafından geliri kasaba okullarına bırakılacak bir han yaptırıldığ 1 ve aynı bölgede altında yedi dükkanı bulunan geniş salonlu bir Gazino Kahvesi yer aldığı bilinmektedir. Günümüze ulaşamayan bu yapılardan Gazino Kahvesine İzmir, İstanbul ve Atina'dan bazı dergi ve gazetelerin geldiği ileri sürülür (Stamatopoulos 1985, 52). Duvar resmine kaynaklık ettiğini belirttiğimiz dergi de kasabaya bu yolla ulaşabileceği gibi, armatör olduğu ileri sürülen ev sahibi Haralambos Sultanidis'in özel kütüphanesinde de bulunabilir.

18. yüzyılın ikinci yarısından itibaren Osmanlı-Rusya ilişkileri gerilimli bir hal almış, iki devlet arasında gerçekleşen savaş ve antlaşmalar, netice itibariyle Osmanlıların aleyhine sonuçlanmıştır (İnalcık 2016, 275-292). Nitekim 1774 yılında imzalanan Küçük Kaynarca Antlaşmasının bazı maddeleri Osmanlı topraklarında yaşayan Hıristiyan azınlığa inançlarını yaşamaları bağlamında baskı yapılmaması, kiliselerinin tamir ve yenilenmesine engel olunmaması hükümlerini içermekte ve Rusya'nın Osmanlı topraklarındaki Ortodoksların hamisi olarak tanınmasını istemektedir (Erim 1953, 156). Bu yaklaşımların Osmanlı topraklarındaki Ortodoks ve Slavlar üzerinde Rusya'ya karşı bir sempati oluşturduğu varsayılabilir. Özellikle Balkanlarda Osmanl1dan koparak bağımsızlığını kazanmış pek çok ulus için yukarıdaki genellemenin doğruluk payı vardır. Hanedanlıklar arası evliliklerin de dostluk ve ittifakları pekiştirmiş olması muhtemeldir. Sözgelimi makaleye konu olan resimdeki iki prens (Nikola ve George) iki kardeşin çocuklarıydı.

19. yüzyılda milliyetçilik akımının etkisiyle Kapadokya'da diğer azınlıklarla birlikte Rum okullarının sayısında artış gözlenir. Artışın temelinde, bölgedeki Rumların çoğunun Türkçe konuşmasından duyulan kaygının yanı sıra, bu dönemde bölgede sayıları artan Katolik ve 
Protestan misyonerlerin dini telkinlerinden koruma düşüncesi yatmaktadır (Augustinos 1992, 163-169). Okullar içinde Atina'dan öğretmen getirenleri de vardır. Sinasos (Mustafapaşa), bölgedeki Rum yerleşimler arasında çoğunluğu Rumca konuşan Ortodoks ahaliye sahip olmasıyla dikkat çeker. Çalışma ve ticaret hayatıyla İstanbul'la yaşadığı ilişki; okul, gazino gibi eğitim ve kültür kurumlarına sahip oluşu, hem antik dönem kaynaklarında geçen öykülerden hem de yakın tarihli olaylardan haberdar olmalarını sağlamıştır.

Resim, bir yanda dinsel, öbür yanda etnik olarak iki hami devlete duyulan bir sempati gibi algilanabilirse de, karşı duvarda görülen Osmanlı arması bir devlet simgesi olarak oldukça dikkat çekicidir (Fig. 4). Bölgedeki başka evlerde ve yapılarda da gördügümüz arma, Selim Deringil'e (1993, 4-5) göre II. Mahmut döneminde bir İtalyan sanatçıya tasarlatılmıştır. Osmanlı devletinin kara ve deniz kuvvetlerini, cesaretini, adaletini, merhametini çeşitli simgelerle betimlemiş, II. Abdülhamid döneminde kullanımı yaygınlık kazanmış bir ikonografik görsele dönüşmüştür. Arma-i Osmani, Devlet-i Aliyyeyi simgelediği kadar, ev sahibi Sultanidis'in Osmanlı vatandaşı olmaktan memnuniyetsizlik duymadığının bir göstergesi olarak da yorumlanabilir. Öte yandan Kostis Meletiades'in resimlediği

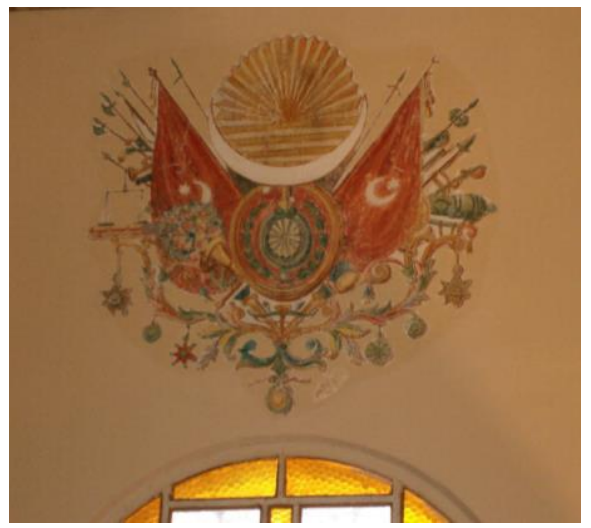

Fig. 4. Mustafapaşa (Sinasos), Haralambos Sultanidis Evi, Arma-i Osmânî resmi başka bir konakta da benzer armanın işlenmiş olması, sanatçının tercihi olarak ta kabul edilebilir.

Resmin altında imzası olan Kostis Meletiades, kasabadaki pek çok ev/konakta çalışmaları görülen kasabalı bir ressamdır. Mübadeleyi görmeden vefat etmiş şanslı kasabalılardan biri olan sanatçının, İstanbul'daki havyarcı akrabalarının birinin yanında çalışırken gizlice İtalya'ya gittiği, orada kaldığı dört yıl boyunca resim yapmayı ve klarnet çalmayı öğrenerek kasabaya döndüğü, resim sanatının her dalında usta, fırça ve renklere tutkun bir kişilik olduğu belirtilir (Balta 2007, 101-103).

Kasabada ve çevresinde Temel Öztürk Evi (1879), Galip Öztürk Evi, Murat Tüzen Evi (1908), Ali Sümer Evi (1910), Fevzi Başoğlu Evi (1888), Ürgüp Güzelöz Evi (1912) Meletiadis'in imzasının görüldüğü konutlardır. Figürlü sahnelerin yanı sıra manzara resimleri yaptığı da anlaşılan sanatçının, çalıştığı evlerin bazılarında oval ya da daire biçimli madalyonlara bilmeceler veya özlü sözler kaydettiği ve nüktedan kişiliğiyle kasabalılarca "soytarı" lakabıyla tanınan bir sanatçı olduğu dikkati çeker (Pekak 2010, 96).

Sonuç itibariyle; Sinasos (Mustafapaşa) Sultanidis Evi’ndeki bu resim, 1890 y1lından itibaren yayımlanmaya başlayan ve Fransa merkezli olmakla birlikte dünyanın her yerinden olayları resimli olarak haber yapan Le Petit Journal Supplément Illustré'den kopyalanmış bir çalışmadır. Dergini her sayısında benzer olayların resimleri olmakla birlikte, bu konunun, kasabanın saygın tüccarlarından biri ve armatör olduğu ileri sürülen Haralambos Sultanidis tarafından bilinçlice seçildiğini söylemek mümkündür. Muhtemelen derginin bu sayısını Haralambos elde etmiş olmalıdır. Zira kasaba ve çevresindeki başka ev/konakta Le Petit Journal Supplément Illustré kaynaklı resim olmaması bu görüşü desteklemektedir. Fransa'dan çok uzakta Japonya'da gerçekleşen bir olayın, on dokuz gün sonra resimli bir haberle yayınlandığı derginin iki yıl sonra yine Fransa'ya uzak bir Kapadokya kasabasındaki duvar resmine kaynaklık etmesi ilginç olmakla birlikte, doğrusu Sinasos (Mustafapaşa) söz konusu olunca şaşırtıcı değildir. 
Kasabadaki konaklardan biri olan Temel Öztürk Evi’ndeki 1887 tarihli Bahar isimli duvar resminin de Fransız ressam Pierre Auguste Cot'un 1873 tarihli Springtime adlı çalışmasının naif bir kopyası olduğu dikkate alınırsa (Özbek 2016, 392), kasabanın geçirdiği ekonomik ve kültürel değişimi, Avrupa ve Avrupa dışı dünyanın yakından izlendiğini ve sanat üzerindeki etkileri anlamamızın daha kolay olacağı şüphesizdir.

\section{KAYNAKÇA}

Arık R. (1999). “Osmanlı Sanatında Duvar Resimleri”. Osmanlı 11 (1999) 423-436.

Augustinos G. (1992). The Greeks of Asia Minor. Confession, Community and Ethnicity in the Nineteenth Century. London 1992.

Balta E. (Ed.) (2007). Sinasos. Mübadeleden Önce Bir Kapadokya Kasabası. İstanbul 2007.

Çokana A. (2016). 20. Yüzyll Başlarında Anadolu ve Trakya'daki Rum Yerleşimleri. İstanbul 2016.

Dawkins R. M. (1910). "Modern Greek in Asia Minor”. The Journal of Hellenic Studies 30 (1993) 109-132.

Deringil S. (1993). "The Invention of Tradition as Public Image in the Late Ottoman Empire, 18081908". Comparative Studies in Society and History 35/1 (1993) 4-5.

Erim N. (1953). Devletlerarası Hukuk ve Siyasi Tarih Metinleri (Osmanlı Imparatorluğu Antlaşmaları). Ankara 1953.

Galerie Drylewicz (n.d.).“Henri Meyer”. Kaynak: http://galerie-drylewicz.com/artiste/henri-meyer/?lang=en

İnalcık H. (2016). Devlet-i Aliyye. Osmanlı İmparatorluğu Üzerine Araştırmalar. İstanbul 2016.

Korat G. (2005). Taş Kapıdan Taçkapıya Kapadokya. İstanbul 2005.

Özbay A. (2004). “Kapadokya’nın Uyuyan Güzeli: Mustafapaşa-Sinasos”. Mimarlı 319 (2004) 68-72.

Özbek Y. (2016). "Mustafapaşa (Sinasos) Duvar Resimlerinde Sıradışı Konular ve Georgios Iordanidis". Mediterranean Journal of Humanities VI/2 (2016) 381-398.

Pekak S. (2010). "Kasaba, Kilise, Ressam”. Arkeoloji ve Sanat 133 (2010) 77-100.

Renda G. (2002). "Yenileşme Döneminde Kültür ve Sanat”. Türkler 15 (2002) 265-283.

Saner T. \& Yıldırım Z. Ö. (2006). "Sinasos Konutlarında Kentli Özellikler". Sanat Tarihi Defterleri 10 (2006) 165-179.

Sin P. Y. S. (1989). The Otsu Incident: Japan's Hidden History of the Attempted Assassination of Future Emperor Nicholas II of Russia in the Town of Otsu, Japan, May 11, 1891 and Its Implication for Historical Analysis. Unpublished PhD. Thesis. University of Pensylvania, Pensylvania 1989.

Stanatopoulos K. (1985). "Everyday Life in Sinasos, Cappadocia". Sinasos in Cappadocia. London (1985) 39-91.

Tekinalp P. Ş. (2002). "Batılılaşma Dönemi Duvar Resmi”. Türkler 15 (2002) 440-447.

Web Galery (n.d.). "Henri Meyer". Kaynak: http://www.artchive.com/web_gallery/H/Henri-Meyer/ Henri-Meyer-reproductions-1.html 